\title{
Analysis of Transport Logistics Cost in Pakistan and CPEC Infrastructure
}

\author{
Noman Ashraf, Ni Lin, Muhammad Suleman, Waqas Farid
}

\begin{abstract}
China Pakistan economic corridor is a mega project signed in the form of an agreement between two countries to gain one mutual goal, economic growth in the region. With the huge investment capability of china and important geopolitical position of Pakistan, CPEC is like a catching straw for the drowning economy of Pakistan and a golden opportunity for China to develop a new Eurasian Land Bridge to expand its markets. The project is based on one belt one road initiative to redevelop the ancient silk road. The population and infrastructure in china is not uniformed around the country. The most of the population lives in southeast of china called as Hu Huanyong Line [1]. While the western region is not much developed as compared to eastern region. Similarly, on Pakistani side the northern areas are not much developed. CPEC has a mutual goal of infrastructure development but it faces two different nations to work on it under different circumstances. The coast line of eastern china is $3500 \mathrm{~km}$ away from the Kashgar, northwestern city of china. While the Gwadar port is $1500 \mathrm{~km}$ away. This does certainly decreased logistics cost for trade. The logistics cost is still different on both sides due to many reasons. In this research study we calculate the Road transport logistics cost in Pakistan and analyze the effect of CPEC infrastructure on Logistics. Further suggestions are concluded to develop cooperation in logistics on CPEC.

Index Terms - China Pakistan Economic Corridor, Case Study, Logistics and Transport, Transport Cost Analysis.
\end{abstract}

\section{INTRODUCTION}

China and Pakistan are very closed neighboring countries in terms of relations and have been proven friends in hard time. "Friendship with China is Pakistan's national Policy and over the past more than five decades, Pakistan has always cherished the friendship with china, which is based on mutual benefits and is deeply rooted in the hearts of two peoples". [Airf Alvi] the president of Pakistan said while meeting the Chinese high-level delegation a year ago. This is very important for the CPEC projects to work if the two nations trust each other. Governments can give the opportunities and build the infrastructure but on the grounds the people are actual stakeholders of this project.

Due to lack of resources and troubled economy Pakistan is unable to develop its domestic logistics infrastructure that causes the logistics cost very high. After the Completion of CPEC phase I, Pakistan is able to improve its roads transport and less travel time between trading hubs.

\footnotetext{
Noman Ashraf, Masters student, Mechanical engineering college Chongqing university, china in the field of Logistics Engineering

Ni Lin, Associate professor at Department of Industrial Engineering college of mechanical Engineering, Chongqing University

Muhammad Suleman, Masters student, Mechanical engineering college Chongqing university, china in the field of Logistics Engineering

Waqas Farid, Masters student, Mechanical engineering college Chongqing university, china in the field of Logistics Engineering
}

In Pakistan railway transport for logistics is not good enough and people do not trust it although it is cheap then road transport. Also, rivers are not used for logistics therefore road transport is the only favorite choice among people when it comes to fastest and cheapest goods transportation.

In recent years many domestic and international companies have started their operation in the field of logistics which is a good signal in the direction of increased trading activities. The logistics costs and density of logistics traffic before and after the CPEC infrastructure development has significantly changes. Opening of new routes and roads has made it easier for the logistics service providers to increase the services.

\section{CURRENT INFRASTRUCTURE}

\section{A. Motorways}

With the help of CPEC project a network of modern roads are being constructed all around the Pakistan. Covering three Corridors i.e. Eastern alignment, western alignment and central alignment [2]. The network of Motorways is currently being constructed on eastern alignment where the population density is high and most of the Pakistan's trade is done. On the other hand, the security situation and other infrastructure is also very well developed. Most of the motorways have been constructed some are partially opened and some are under planning phase. After the CPEC phase I the road networks have improved dramatically in Pakistan and traveling has significantly dropped.

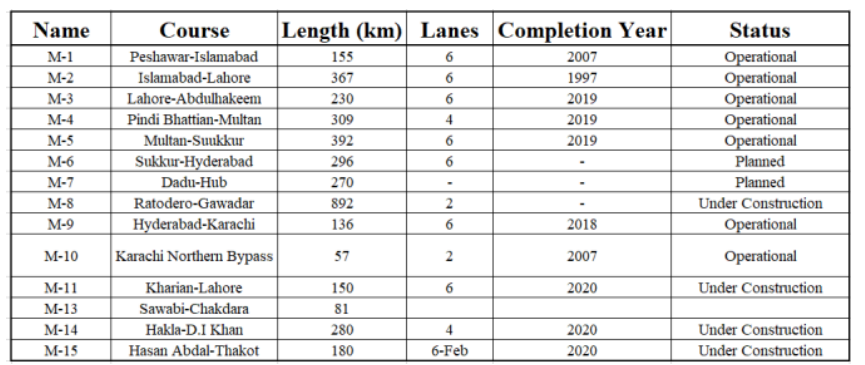

Source: NHA

Figure 1

\section{B. National Highways}

The National High Way authority is the main authority in Pakistan for the development, maintenance and planning of roads across the country. The NHA works under the ministry of communications in federal government. Pakistan has a large network of national highways across the country consisting of more than 12 thousand kilometers. Including strategic highways as S1, S2 and S3. N-5 is the largest highway of Pakistan from Karachi to Torkham around 1819 $\mathrm{km}$ total in length. These highways are separated from the provincial roads and are maintained by the federal authority. 
National highways of Pakistan mostly connect all the populous areas of Pakistan with a large network of roads.

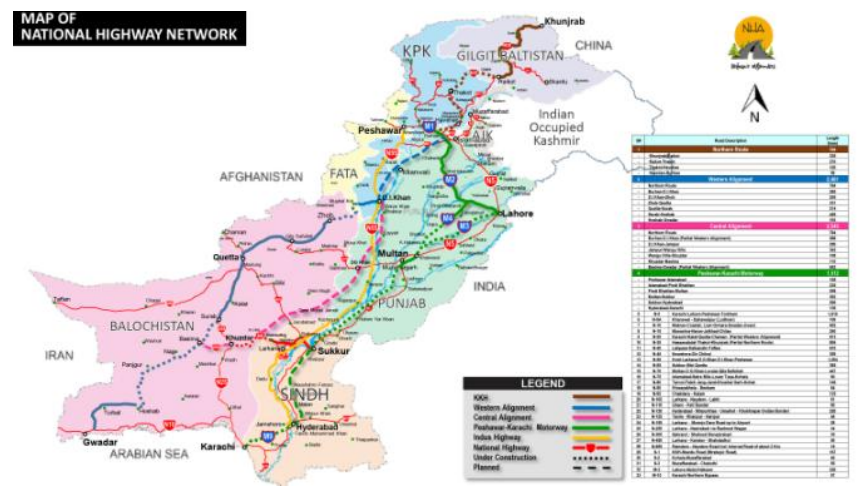

Source: NHA

Figure 2

\section{TRANSPORT LOGISTICS COST ANALYSIS}

To calculate the cost of road transport logistics in Pakistan it should be noted that both countries have difference of infrastructure and facilities. Labor costs and other factor vary in both countries. To understand the logistics cost of CPEC routes and importance of current cost we took a case study to calculate the cost for road transport logistics between the main trading routes of Pakistan. In this analysis the costs are calculated keeping in mind all the possible costs on actual grounds. For this purpose, we took the case study of heavy-duty vehicles currently used by different logistics companies in Pakistan. The types of vehicle and their load capacity with respect to fuel consumption is calculated.

In the figure the two largest trades hub of Pakistan and Karachi are connected in eastern route of CPEC while the norther part of Pakistan Gilgit is also connected through Sahiwal City. The distances and toll taxes are calculated for round trips while the driver wage is calculated per day including food allowance.

The five different types of vehicles in this operation have been considered with different load, length and engine power capacities. The maximum allowed length in Pakistan by the NHA is 58.5 feet [3]. While the fuel costs in this case study are considered for the specific time, as they vary every day. The fuel consumption is also not a constant, it varies depending on the density of the route but in this case study an average of trips is used to calculate the fuel efficiency of specific vehicle. Through which we can calculate average fuel consumption on full load between two points. The toll tax points between specific points are constant and pricings are also available by NHA to calculate. While the labor cost of driver in Pakistan is very cheap as compare to other countries. Depending on the route and vehicle sometimes two drivers are used which can be added in the total cost.

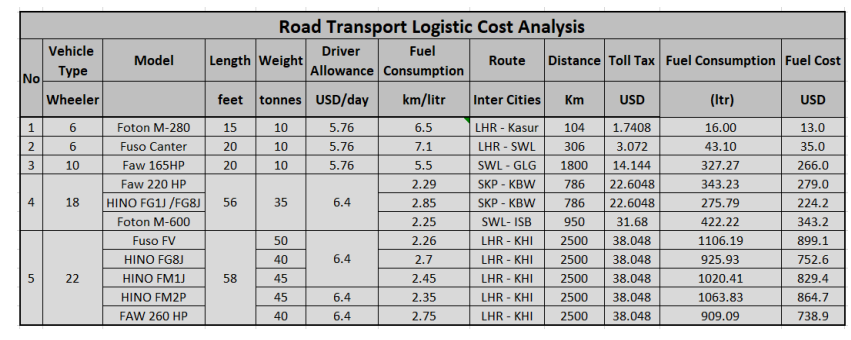

\section{A. Cost Calculation}

Logistics cost for the trip $=$ Fixed Cost + Variable Cost $=\mathrm{Fc}+\mathrm{Vc}$

Here,

$$
\text { L.C }=\left(D a+T t+x_{0}\right)+(d / \square) \mathbf{f p}
$$

Fixed Cost $=\mathbf{F c}$

Variable Cost $=\mathbf{V c}$

Fuel Consumption $=\square$

Driver Allowance $=\mathbf{D a}$

Distance $=\mathbf{d}$

Fuel Price $=\mathbf{f p}$

Toll Tax $=\mathbf{T t}$

Unknown fixed costs for trip $=\mathbf{x}_{\mathbf{0}}=(\mathbf{x} 1+\mathbf{x} 2+\mathbf{x} 3 \ldots . . . \times n)$

Here the unknown fixed costs are related to those costs that occur during the trip. Sometimes due to fine of vehicle or need of parking during unnecessary stops. As in Pakistan due to political situation the loader vehicle face problem for continuous movement. This hurdle makes increase in logistics cost and companies have allocated fixed price for this cost in total logistics cost.

From our case study the calculated operational cost on average is around $0.2 \$ / \mathrm{km}$ for a loaded vehicle which is the cheapest. Here the long-term maintenance or breakdown or other unknown costs are not included.

\section{ACTIVITY BASED COSTING}

Activity Based Costing is very effective way of calculating the cost for a specific product or service. In transportation and logistics industry it is very rare that organizations use $A B C$ to calculate logistics cost because it is very difficult for the companies to determine and evaluate true cost of specific operation or service [4]. In the above case study, it is also based on the experience of an organization to calculate the cost for a specific trip on the basis of Traditional costing analysis. Here it is very important to note that to fully implement $\mathrm{ABC}$ in transport logistics especially in countries like Pakistan is very difficult approach. The main reason is the instability and continuous variance in the process. Also, the logistics service providers in Pakistan have different types of customers. And the requirement changes on a same route from customer to customer. The collection of Data and cost for implementing $\mathrm{ABC}$ in transport logistics in Pakistan is not very easy task to perform.

The data in the case study is calculated as TCA but in final conclusion it was suggested to the organization to implement $\mathrm{ABC}$ to further costing of the services accurately and more precisely. ABC process may be a little complicated to implement because in Pakistan digital tracking of data is not very common in some organizations but with new trends in the market and continuous growing competition many 
logistics companies are moving forward to use modern tools for pricing. So, it might be possible that in future logistics companies in Pakistan use Activity based costing in transportation logistics.

\section{TRANSPORT LOGISTICS IN PAKISTAN}

Road Transport in Pakistan is the backbone of logistics. Most of the people and companies prefer road transport over railway or other modes of transportation because of many reasons such as cost, time, reliability and easy accessibility. On the other hand, railway in Pakistan is not much developed due to the less allocated budget for development. The railway inland traffic reduced from 41 percent to 10 percent for passengers and 73 percent to 4 percent for freight traffic since seventies [5]. Although in CPEC phase II the rail track from Karachi-Peshawar will be upgraded for the train speed up to 160 kilometers per hour [6]. But this is still under planning phase and the work has yet to be started. The trucking in Pakistan is famous for transporting all sorts of gods for short and long routes. The five different entry points to the country are covered through trucking to provide all sorts of inland logistics. Before the CPEC infrastructure development trucking was very much unorganized and based on groups of local service providers. But in recent years many big names have jumped into Logistics business after the development of CPEC and currently they are providing logistics services in a very organized way. The growing demand for logistics provider is a very positive sign for the logistics transport. So far there is no other competition for the road transport in Pakistan. Because no other transport sector is developing with such pace like road networks.

There are many reasons and challenges to this problem such as Pakistan's political situation, weak economic growth, security problem, cultural issues and interference of external forces [7]. The only corridor that has been yet developed under CPEC is eastern corridor which passes through the main population area of Eastern side while the wester corridor is yet to be started. Because of the improved security situation and stable political leadership now the Pakistan has a very good opportunity to gain its trust for the foreign investors and can carry out the further infrastructure development on phase II.

There is one more important thing to note about the geography of Pakistan that although it has a significant number of rivers which flow from north to south and also the ports are located on the southern part of Pakistan. Most of the routes in CPEC are from northern to southern side but contrary to China Pakistan does not use its river for inland shipping. Road transport is the only mode used for logistics transport. The reason according to a research study is that the main possible inland navigation route was Indus river but after the development of irrigation and canal system and building of dams under Indus Water Treaty, it could not get the attention of the authorities to look for the inland navigation trade though rivers. While the shifting nature and delta are also the main problem to course through rivers logistics. After the development of railway, it fulfilled the inland requirement of trade and logistics [8].

\section{CONCLUSION}

As per this study suggests the cost of transport logistics in Pakistan is very cheap which saves the money and time for companies to support their trade. The low labor cost in Pakistan is noticeable which is a high factor when it comes to European wages for truck drivers. The risks associated to logistics transport are very less as compared to the longer route for china for their energy supply chain. As the government has started building new industrial zones all across the country especially in Gwadar which is highly beneficial for the Chinese investors to take advantage of remote manufacturing with very less taxes and low logistics costs. On the other hand, Pakistan can also take benefit from this golden opportunity to develop infrastructure and human resource building. By the start of fully operational corridors Pakistan can enjoy the benefits of easy access to international markets as well as enhanced domestic and international trade similar to Chinese trade model. Also, the backward province Baluchistan will be the center of this project and its people will get the better opportunities for jobs and better life facilities. Further with the implementation of modern logistics models in Pakistan the transport sector can enhance its capability in a leading role. Currently the transport logistic sector requires to use more modern tools and centralized digital monitoring of data for the on going logistics activities within the organization. It won't be wrong to say that now is the time for Pakistan to revolutionize its transport with modern age demand.

\section{ACKNOWLEDGMENT}

This is to acknowledge Allied Engineering and Services (Pvt.) Ltd. for their cooperation and providing important data for the research studies. And Department of Mechanical Engineering, Chongqing University, China

\section{REFERENCES}

[1] Minmin Li, Biao He, Renzhong Guo, You Li, Yu Chen, Yong Fan "Study on Population Distribution Pattern at the County Level of China, ," Sustainability 2018, 10, 3598; doi:10.3390/su10103598

[2] Abid, M., and Ashfaq, A., (2015). CPEC: Challenges and Opportunities for Pakistan, pu.edu.pk/images/journal/studies/PDF-FILES/Artical-7_v16_2_2015s

[3] http://nha.gov.pk/en/

[4] Adil Baykasoglu,Vahit Kaplanoglu. Application of activity based costing to a land transportation company: A case study, 2008, International Journal of Production Economies

[5] Muhammad Abbad, Nawar, Arshad, Aisha, Analyzing Pakistan's Freight Transportation Infrastructure Using Porter's Framework and Forecasting Future Freight Demand Using Time Series Models, 2010, Proceedings of the 2nd WSEAS International Conference on URBAN PLANNING and TRANSPORTATION

[6] Dr.Sutinder, John Mohd, China- Pakistan Economic Corridor (CPEC), Its Impacts on Pakistan Economy, 2017, International Journal of Innovative Research and Advanced Studies (IJIRAS) Volume 4 Issue 7

[7] Aimin Deng, Yunfeng Li, Problems and Countermeasures in the Development of Transport Logistics in China-Pakistan Economic, 2017, World Journal of Research and Review (WJRR) ISSN:2455-3956, Volume-5, Issue-6, December

[8] Sheheryar, Bilal, Hassan, Analysis of Transportation Potential of Rivers in Pakistan, 2017, International Conference on Sustainable Development in Civil Engineering, MUET, Pakistan

Noman Ashraf is currently a Masters student at Mechanical engineering college Chongqing university, china in the field of Logistics Engineering. He has done his bachelors in Mechanical engineering from one of the top 
universities in Pakistan. His research Directions are Logistics and Supply Chain Management under the supervision of Professor Ni Lin.

Ni Lin He is Associate professor at Department of Industrial Engineering college of mechanical Engineering, Chongqing University. His research directions are Project Management, Logistics and Supply chain. Product Development

Muhammad Suleman He is Masters student at Mechanical engineering college Chongqing university, china in the field of Logistics Engineering research directions are modern Logistics and modern Industry. $\mathrm{He}$ is studying under the supervision of Professor Deng Li.

Waqas Farid He is Masters student at Mechanical engineering college

Chongqing university, china in the field of Logistics Engineering research directions are modern Logistics and modern Industry. He is studying under the supervision of Professor Deng Li 